\title{
De influências e sobrevivências: a transposição de uma memória de imagens por entre movimentos artísticos-culturais
}

Maria Lucia de Paiva Jacobini

\author{
WARBURG, Aby. \\ Histórias de fantasma para \\ gente grande: escritos, \\ esboços e conferências. \\ São Paulo: Companhia das Letras. \\ 417p., 2015.
}

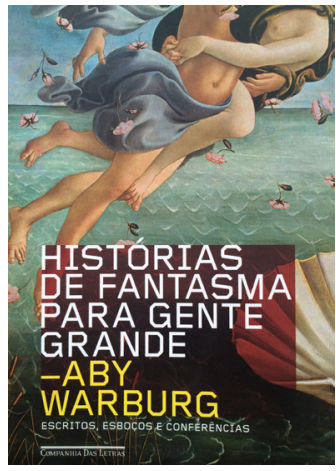

Resumo: A coletânea de ensaios de Aby Warburg colabora para concretizar sua vontade de construir uma biblioteca de referências capaz de demonstrar como imagens sobrevivem e ajudam a transportar memórias ao longo da história. Partindo sempre das imagens e das referências da Antiguidade pagã, o autor verifica a força de sua influência sobre a produção artística do Renascimento, de releituras cosmológicas e de simbolismos religiosos.

Palavras-chave: Warburg; memória; Antiguidade pagã; Renascimento. 
Abstract: On influences and survivals: an imagery memorial transposition among artistic and cultural movements - This Aby Warburg's essay collection comes to make real his will to raise a library as international reference on how images can survive and convey memory throughout history. The author reinforces the influence of pagan ancient images all over the artistic production of Renaissance, since cosmological interpretations to religious symbolisms.

Keywords: Aby Warburg; memory; pagan Antiquity; Renaissance.

Em um livro que reúne diversos escritos de Warburg, o último capítulo aborda sua ousada proposta de criação de um atlas de imagens. Mnemosine, como o autor o denomina, seria uma reunião de imagens capazes de ilustrar como a memória aciona a herança de inspirações da Antiguidade e demonstrar como tal herança se manifesta em diversas representações da vida em movimento da época do Renascimento. São, portanto, formas expressivas que sobrevivem a transformações artísticas, culturais, temporais e espaciais e continuam presentes muitos séculos depois.

Warburg descreve essa capacidade de sobrevivência de diferentes maneiras: transporte, hereditariedade, vínculo, influência, restituição, restabelecimento, simbiose, reaparecimento e analogia. Assim, do mesmo modo como usa tais termos para descrever como a Antiguidade transita até o Renascimento, suas ideias transitam entre os vários artigos do livro, como uma linha que cria um diálogo de referências e começa a construir uma pequena parte de seu atlas Mnemosine.

Por isso mesmo, talvez o interessante aqui seja não observar capítulo a capítulo, palestra a palestra ou proposta de estudo a estudo, mas tentar encontrar exatamente os temas que o autor identificou como aqueles que foram inconscientemente transportados entre épocas e lugares pela memória artística. Seja num palácio italiano, nas profecias astrológicas ou nos povoados dos índios da América do Norte.

O movimento do olhar, das roupas, dos cabelos e a torção dos corpos é o que, segundo Warburg, foi restituído por Botticelli, Dürer e até Manet, posteriormente. É o tema que foi herdado da Antiguidade pagã para conseguir representar a partir do drama. Olhando inicialmente para os quadros do Nascimento de Vênus e A Primavera, de Sandro Botticelli, o autor encontra uma espécie de correspondência, de ideias análogas que ajudam a esclarecer a presença desse espírito da Antiguidade no século XVI.

Warburg já dá demonstrações de que pretende construir uma biblioteca de imagens por meio de um mapa de referências, de fontes de influências e de outras imagens que transportam a representação da nudez e do movimento de corpos, cabelo e roupas por entre épocas. Por entre Ovídio, Poliziano até Botticelli. São motivos repetidos em poemas, hinos, manuais artísticos, gravuras, sarcófagos e mais uma vez concretizados em quadros que foram tão formadores do estilo de uma época.

Porém, Botticelli não foi único, e a releitura de Albercht Dürer sobre a Morte de Orfeu transporta para a arte flamenga a fórmula do pathos. Como uma maneira de lidar com 
as emoções, tal fórmula representa uma preservação da arte clássica e da arte popular e pagã. Dessa vez, seu atlas de referências convida o leitor a entender como o pintor alemão remodelou o mesmo gestual patético da arte grega, bebendo também dos poetas Ovídio e Poliziano e dos pintores Mantegna e Pollaiuolo para apreender a figura dramática e os temas da Antiguidade pagã.

Assim, as representações da Morte de Orfeu podem ser entendidas com um processo de evolução no curso da história que, segundo o autor, parte de Atenas, passa por Roma, por Mantova, por Florença e chega à Alemanha. E, principalmente, atinge a alma de Dürer.

Não exatamente no Renascimento, porém possivelmente na época de completa reformulação das manifestações pictóricas do século XIX, Manet representa o ponto de uma linha que culmina no fim do virtuosismo acadêmico. Mais do que isso, que mostra a possibilidade de redescobrimento de um estilo gerador de valores expressivos: a onipresente Antiguidade pagã.

Warburg identifica a origem no modelo de um sarcófago da Antiguidade transportada para as enigmáticas três figuras de Le Déjeuner sur l'herbe. Figuras essas que já haviam sido inclusive reinterpretadas por um mediador italiano. Rafael, com seu quadro O Julgamento de Paris, teria sido o primeiro a preservar a mitologia pagã por meio de gestos, poses e fisionomias que tanto parecem explicar o motivo de Manet. Desse modo, os mencionados pintores de espaços e tempos diferentes - são os responsáveis por gerar e conservar o movimento expressivo de uma mesma Antiguidade. Lida e relida a partir de eventos tão diferentes.

Contudo, é o mesmo evento que cria a linha mnemônica das palestras de Warburg sobre sua marcante viagem à América do Norte. Menos como um ensaio acadêmico e consideravelmente mais como uma narrativa pessoal e envolvida, o autor encontra na sua própria experiência, memorizada, contada e registrada por seu acervo de imagens, como é possível encontrar nos chamados pueblos dos estados do Novo México e do Arizona as representações mágicas provenientes do paganismo europeu.

Provavelmente transportada por missionários católicos durante o processo de colonização, a visão de mundo pagã parece sobreviver, aos olhos de Warburg, não só à influência da cultura religiosa ou norte-americana, mas principalmente às transformações tecnológicas e de um tipo específico de progresso que já dominavam o mundo da época e começavam a se fazer presentes também nos isolados povoados. Bonecos de santos, dançarinos e, mais do que tudo, serpentes são então as responsáveis por criar um vínculo direto entre o evento tão raro e esperado da chuva e a imagem do mundo cosmológico local.

As serpentes são desenhadas como símbolos do relâmpago, exaltadas em altares que evidenciam a cosmologia pagã do devir, do subir e do descer entre a natureza e as alturas. São essas serpentes que são clamadas em um participativo ritual de dança que, ao usar de máscaras, propõe uma infiltração no mundo da magia por meio da metamorfose: de homens que imitam serpentes, que as adotam como vínculo quase de parentesco com o mundo animal e se aproximam de suas divindades e da natureza. 
Finalmente, a astrologia é o tema que testemunha o último percurso percorrido entre a Antiguidade e o Renascimento. Ou até entre essa mesma crença no poder da natureza adotada pelos povos norte-americanos e que já fazia parte da cultura artística de Florença ou na Alemanha de Lutero.

Warburg identifica como artistas incorporam não só temas do paganismo, como também se alimentam da astrologia para elaborarem seus tapetes, suas figuras e seus afrescos. Contudo, o autor não deixa de entender que nesse processo de contínua releitura, há também uma demonstração de como "a humanidade tem sido enfeitiçada por essa traiçoeira lógica pseudomatemática" (2015, p. 104), o que pode acontecer tanto para ilustrar expressões e comportamentos, quanto para reforçar profecias que poderiam transformar o mundo político-religioso.

É o caso de como essas mesmas pretensões proféticas da astrologia fizeram parte da Reforma alemã. Isso é, como profecias fatalistas - tão lidas e relidas pelas manifestações artísticas do Renascimento - da Antiguidade pagã acabaram por ir além do âmbito da história da arte e alcançar uma nova influência, agora sobre o sistema prático-religioso da Alemanha.

Embora Lutero tenha sido um crítico e um cético quanto ao poder premonitório da astrologia, esteve cercado por muitos que procuraram em sua data de nascimento e, consequentemente, em sua previsão de futuro, sinais de que ele seria o líder de um processo de libertação religiosa local.

O que Warburg ressalta é que tal processo de liberação religiosa estaria também ligado a um fenômeno natural, previsto e previsível, de um cometa ou de uma catástrofe diluviana. Ou seja, o culto supersticioso parecia também contribuir para uma outra reação diante de Lutero, a de repúdio e relacionada aos aspectos mais demoníacos da Antiguidade pagã. Agora enfatizada por representações pictóricas alarmistas, astrológicas ou até monstrológicas.

Em Histórias de Fantasma para Gente Grande, Warburg solidifica para o leitor essa força da linha de pensamento antropomórfica e simbólica que tanto ajuda a construir a memória ocidental. Uma memória construída e reforçada a partir da herança de uma produção grega pagã e continuamente reconfigurada em uma espécie de pós-vida, de sobrevivência e de transporte de sentidos ao longo da história.

Se com seu atlas Mnemosine o autor pretendia falar dessa mesma memória que transita, que é transportada em uma interminável migração histórica e simbólica, com esses artigos ele consegue ir além de uma comprovação de como a Antiguidade está sempre presente em outros movimentos artísticos: demonstra o movimento da memória, em frequentes tentativas de releituras e, principalmente, de revitalização. 
Maria Lucia de Paiva Jacobini é economista formada pela Unicamp, Jornalista pela Puc-Campinas e especialista em Jornalismo Científico pelo Labjor/Unicamp. É Mestre e Doutora pela Comunicação e Semiótica da PUC/SP com bolsa CNPq. Atualmente é jornalista, membro do Grupo de Pesquisa Barroco e Mestiçagem da PUC/SP e docente do Curso de Jornalismo da PUC-Campinas.

mlpjacobini@yahoo.com.br 